\title{
O documento-verdade/A verdade-documento: sobre a institucionalização da informação com vistas ao acesso aberto $^{1}$
}

\section{The document-truth /The truth-document: on the institutionalization of information in order to open access}

Jackson da Silva Medeiros Doutor em Comunicação e Informação pela Universidade Federal do Rio Grande do Sul - UFRGS. Professor do Departamento de Ciências da Informação Universidade Federal do Rio Grande do Sul - UFRGS. E-mail: jackson.medeiros@ufrgs.br

\section{Resumo}

O trabalho tem por objetivo investigar como o documento e suas relações se colocam em estruturas que o instauram como verdade no processo de comunicação científica. Isso servirá como subsídio para, posteriormente, discutirmos perspectivas ligadas à relação poder-ética-informação no que qualificamos como uma crise na comunicação científica, com olhar especial para a privatização e o acesso aberto ao conhecimento. Apresenta metodologia qualitativa teórica e uma abordagem bibliográfica não exaustiva como forma de compreender estruturas de investigação sobre o fenômeno. Considera que o documento (científico) se materializa como um dispositivo do regime de verdade que é validado por forças que detêm poder em determinado campo.

Palavras-chave: Documento. Verdade. Conhecimento científico. Comunicação científica.

\begin{abstract}
The work aims to investigate how the document and their relationships are placed in structures that put it as truth in the scholarly communication. This will serve as input for later discussion prospects concerning the relation between power-ethics-information that we qualify as crisis in scholarly communication, with a special look at the privatization and open access to knowledge. It presents theoretical qualitative methodology and a non-exhaustive bibliographic approach as a way to understand structures about the phenomenon. It considers that the (scientific) document is materialized as a dispositive of a regime of truth and is validated by forces that holds power in a field.
\end{abstract}

Keywords: Document. Truth. Scientific knowledge. Scholarly communication.

\footnotetext{
${ }^{1}$ Este trabalho é parte de projeto de pesquisa fomentado pelo CNPq. 


\section{Introdução}

Jacques Le Goff, na parte final do capítulo Documento/Monumento, integrante da obra História e Memória, diz: "Todo o documento é mentira”. Esta afirmação, advinda de um processo compreensivo de seleção de memória, refere-se ao preenchimento do documento pelos aspectos que estão condizentes com práticas tanto de uma época da sociedade quanto do aparato mental daquele que produz o documento.

Essa ideia nos leva a pensar, por oposição, no documento como um rito de verdade. Uma verdade que se dá na crença de um tipo de correspondência entre o que é efetivamente real e o que está enunciado em um discurso. Nesse sentido, enunciar uma verdade requer um congelamento de ações e o relato sobre um mundo que circunscreve o próprio mundo.

Entendemos que o documento, principalmente a partir da disseminação do livro através do invento de Gutenberg, age como construtor de uma realidade, como fiador de uma verdade estabilizada. Atua como um ponto central na história do ser humano e na sua crença de verdade no sentido de uma exploração sempre controlada, sempre instituída.

Nosso intuito, neste trabalho, é investigar como o documento e suas relações se colocam em estruturas que o instauram como verdade no processo de comunicação científica. Isso servirá como subsídio para, posteriormente, discutirmos perspectivas ligadas à relação poderética-informação no que qualificamos como uma crise na comunicação científica, com olhar especial para a privatização e o acesso aberto ao conhecimento.

O trabalho, originado de indagações realizadas pelo autor sobre a importância do documento como estrutura comprobatória de um fato, apresenta cunho teórico como forma de compreender estruturas não rígidas, mas basilares de investigação sobre o fenômeno. Apresenta metodologia qualitativa e uma abordagem bibliográfica não exaustiva como forma de alicerçar sua trajetória. Inicia buscando a ideia de verdade em relação ao documento. Passa, então, para uma construção de elementos que representam a relação da verdade como esfera de poder e o documento como seu representante, a partir da ideia de dispositivo, para argumentar a relação entre o custo do conhecimento e o acesso aberto. Posteriormente apresenta as considerações finais e as referências. 


\section{Da verdade da informação, do documento}

com vistas ao acesso aberto

Quando Michel Foucault ministra sua aula inaugural no Collége de France em 1970, intitulada A ordem do discurso, busca situar sua perspectiva de investigação dali em diante. Assim, parte da ideia que "em toda sociedade a produção do discurso é ao mesmo tempo controlada, selecionada, organizada e redistribuída por certo número de procedimentos que têm por função conjurar seus poderes e perigos, dominar seu acontecimento aleatório, esquivar sua pesada e temível materialidade" (FOUCAULT, 2014, p. 8-9).

Desse modo, o discurso não está sendo analisado em si, mas em uma pretensa organização de verdade. No momento em que entendemos o discurso como a verdade instituída, podemos pensá-lo como fundamentador de uma verdade política capaz de englobar e engendrar outros dispositivos de poder também produtores de verdade.

Há, com isso, uma disputa de verdades tensionada pela perspectiva do poder. A violência $^{2}$ do discurso é um enaltecimento da verdade perpetuada. O discurso é, como anota Foucault, uma violência constante, celebrada em todos os casos. Assim, a verdade está posta a partir daquilo que o discurso diz. Daquilo que o discurso quer dizer. Com isso, a analítica de Foucault visa compreender o discurso que "Por mais que [...] seja aparentemente bem pouca coisa, as interdições que o atingem revelam logo, rapidamente, sua ligação com o desejo e o poder" (FOUCAULT, 2014, p. 9-10).

A questão de verdade em Foucault, advinda de Nietzsche, mostra que a ciência encerra um deus, uma vez que existe todo um sistema institucionalizado onde a palavra só pode ser dita por quem detém a autoridade para tal, como é o discurso de uma classe profissional, como a médica ou a bibliotecária, por exemplo. Esses aparatos, por assim dizer, são o que Foucault determina, ainda pensando seguidamente em Nietzsche, como "novas formas na vontade de saber" (FOUCAULT, 2014, p. 15).

[...] essa vontade de verdade, como os outros sistemas de exclusão, apoia-se sobre um suporte institucional: é ao mesmo tempo reforçada e reconduzida por toda uma espessura de práticas como a pedagogia, é claro, como o sistema dos livros, da edição, das bibliotecas, como as sociedades de sábios outrora, os laboratórios de hoje. Mas ela é também reconduzida, mais profundamente sem dúvida, pelo modo como o saber é aplicado em uma sociedade, como é valorizado, distribuído, repartido e de certo modo atribuído. (FOUCAULT, 2014, p. 16-17).

\footnotetext{
${ }^{2}$ Foucault explica que não se deve definir o poder apenas através da repressão; o poder advindo apenas da repressão é uma forma jurídica que não necessariamente acarreta em obediência. Para o filósofo, "o que faz com que o poder se mantenha e que seja aceito é simplesmente que ele não pesa só como uma força que diz não, mas que de fato ele permeia, produz coisas, induz ao prazer, forma saber, produz discurso." (FOUCAULT, 2012, p. 45).
} 
Foucault (2003, p. 233), então, diz explicitamente o que entende por verdade:

[...] conjunto de procedimentos que permitem a cada instante e a cada um pronunciar enunciados que serão considerados verdadeiros. Não há absolutamente instância suprema. Há regiões onde esses efeitos de verdade são perfeitamente codificados, onde o procedimento pelos quais se pode chegar a enunciar as verdades são conhecidos previamente, regulados.

Aqui temos que entender uma perspectiva que Frohmann (2008) trata de forma congruente ao panorama de Foucault: a materialidade do documento atua como resultado de processos contínuos, violentos e empoderadores de já empoderados. É o que Foucault disserta em A arqueologia do saber sobre uma guinada na compreensão do documento. Para o pensador, o que define o documento não é sua qualidade como matéria, mas as séries, as redes de relações que estabelece. Nesse momento o que é controlado, gerido, produzido sob um sério jogo de verdades entra em cena, onde se define a produção de verdade que leva a um determinado resultado.

Há, nesse sentido, uma ampliação do escopo de análise do documento para além do documento. Isto é, o documento não circunscreve um suporte capaz de limitar o registro da reflexão de indivíduos, mas comporta uma acepção de causas e efeitos no e do documento. Essa abordagem desloca o documento para além de sua relevância como objeto informacional, colocando-o como elemento-chave nas análises epistemológicas, históricas, sociais, políticas, culturais etc. Implica ver, como anota Araújo (2011, p. 225), a ocorrência das formações discursivas, uma vez que "não representam um acabamento do discurso", mas configuram "uma situação de ordem do discurso, característica do saber de uma época”.

Para Foucault (2014), o que é verdadeiro deve estar situado em um espaço de verdade para ser considerado verdade. Isso só é possível ao entrar no jogo, ou seja, só é legítimo quando obedece a um conjunto de regras que estão colocadas para o controle de produção discursiva. Regras que são instituídas a cada discurso, a cada verdade, a cada informação, não podendo dizer, como destaca Araújo (2011), sobre a existência inequívoca de conhecimentos, pois o discurso encobre a existência passada, presente e/ou futura de algo, circunscrevendo-o (o conhecimento) em um campo ${ }^{3}$ onde agentes sociais estão imersos.

Ora, a seleção de documentos, ou antes, a seleção de fontes para a criação de documentos instaura uma formalização estabilizadora de acontecimentos, de fatos, conferindo a eles o estatuto de verdade; na realidade, uma verdade produzida a partir do consenso social.

\footnotetext{
${ }^{3}$ Não é perspectiva desta etapa do trabalho averiguar as questões relativas ao campo advindas de Pierre Bourdieu. A temática deste autor será tratada em trabalhos posteriores e investigada minuciosamente.
} 
Como a própria ideia denota, do consenso advém o caráter disciplinador, atuando como força de cerceamento.

\begin{abstract}
A intervenção do historiador que escolhe o documento, extraindo-o do conjunto dos dados do passado, preferindo-o a outros, atribuindo-lhe um valor de testemunho que, pelo menos em parte, depende da sua própria posição na sociedade da sua época e da sua organização mental, insere-se numa situação inicial que é ainda menos 'neutra' do que a sua intervenção. O documento não é inócuo. É antes de mais nada o resultado de uma montagem, consciente ou inconsciente, da história, da época, da sociedade que o produziram, mas também das épocas sucessivas durante as quais continuou a viver, talvez esquecido, durante as quais continuou a ser manipulado, ainda que pelo silêncio. (LE GOFF, 1996, p. 537-538).
\end{abstract}

Então nos aliamos a Le Goff ao nos aproximarmos da ideia que tanto o consciente quanto o inconsciente produzem efeitos de força, de poder e de verdade, uma vez que uma ação de investigação nesse âmbito só pode ser realizada através de análise das "condições de produção histórica [...] através de uma crítica interna"4 (LE GOFF, 1996, p. 537). Refletindo nesse sentido, documentos podem ser vistos como abarcadores de relações sociais, as quais os atravessam e as quais são atravessadas por eles.

Isso reflete, de acordo com Freitas (2012), um rompimento da compreensão do ato de escrever, isto é, da criação de documentos como uma ação ligada exclusivamente ao processo de guardar uma memória que o cérebro humano não é capaz de sozinho reter. $\mathrm{O}$ documento atua como agente social, produzindo efeitos diversos na sociedade, um produto e um produtor de saber e, por consequência, de poder, caracterizando-se como "uma rede produtiva que atravessa todo o corpo social” (FOUCAULT, 2012, p. 45).

Podemos notar que há uma cisão entre as noções de memória e de história. Respaldada em Pierre Nora, historiador francês, Freitas (2012) diz que a primeira é uma "memória verdadeira", fio condutor de uma cultura ligada ao passado e ao presente de forma afetiva. A segunda noção está ligada a uma "memória prótese", depositada em registros criados por seres humanos, como documentos e monumentos. Ou seja, uma noção atua em oposição a outra, sendo a memória afetiva uma continuidade e a história uma construção intencional de ruptura como produto e produtora de relações sociais.

O documento, então, passa ao largo de ser um registro da memória. É, sim, um dispositivo controlado e controlador, produto e produtor, instaurado e instaurador, ordenado e ordenador, causa e efeito. O documento como verdade é uma institucionalização dos

\footnotetext{
${ }^{4}$ Entendemos que a ideia de Le Goff é próxima e encaminha para o que Pierre Bourdieu entende por campo e habitus. Uma vez que nossa discussão não vai nessa direção, pretendemos aclarar as noções bourdiesianas em outro trabalho.
}

InCID: R. Ci. Inf. e Doc., Ribeirão Preto, v. 8, n. 2, p. 25-41, set. 2017/fev. 2018. 
[...] funcionamentos sócio-históricos da escrita que constituem a centralidade do documento nos variados processos de legitimação de saberes, produção de verdade, distribuição de direitos e deveres em suas densas relações com a produção e reprodução de poderes de diversas ordens - políticas, culturais, econômicas - nas sociedades ocidentais. (FREITAS, 2012, p. 59-60).

Compreender o documento como fundado na linguagem e percebê-la na composição da relação entre indivíduos que se comunicam, permite visualizar o discurso como prática política. É importante que se destaque o que está exterior ao texto, exterior ao documento, isto é, uma extrapolação da linguagem enquanto linguagem, uma vez que esta "[...] funciona como um veículo e alvo de relações complexas de saber e poder na chamada 'sociedade disciplinar'”. Isto está ligado à “[...] prática discursiva, em que fatores institucionais, sociais, epistêmicos, históricos devem ser considerados" (ARAÚJO, 2011, p. 205).

Assim sendo, ao acompanharmos fielmente a acepção de Araújo (2011, p. 27) de que "Verdade e falsidade são atributos da linguagem e não das coisas", filiamo-nos também a Le Goff (1996, p. 535-538):

O documento não é qualquer coisa que fica por conta do passado, é um produto da sociedade que o fabricou segundo as relações de força que aí detinham o poder. [...] Resulta do esforço das sociedades históricas para impor ao futuro - voluntária ou involuntariamente - determinada imagem de si próprias. No limite, não existe documento-verdade.

Na obra Vigiar e punir (1997, p. 181), Foucault fala da relação entre a escrita como forma de instauração de poder disciplinador. Para o autor, “"um poder de escrita’ é constituído como uma peça essencial nas engrenagens da disciplina", o que permite a "formalização" do individual dentro das relações de poder”. Frohmann (2008, p. 25) compreende que a escrita disciplinar "coloca os indivíduos num campo de vigilância através da inserção de registros sobre eles em pesados circuitos institucionais altamente rotinizados".

Vemos, então, que a informação escrita é disciplinadora no sentido de que é onde está contido o saber. Este, por sua vez, impõe limites a cada disciplina no reconhecimento do que é verdadeiro e do que é falso. Tudo que não cabe na análise da dualidade verdadeiro-falso é rechaçado, isto é, existem condições para a existência da informação, do discurso, da verdade. Condições que devem, obrigatoriamente, ser satisfeitas para compor a disciplina.

O que está em questão é o que rege os enunciados e a forma como eles se regem entre si para constituir um conjunto de proposições aceitáveis cientificamente e, consequentemente, suscetíveis de serem verificadas ou infirmadas por procedimentos científicos. Em suma, problema de regime, de política do enunciado científico. Nesse nível não se trata de saber qual é o poder que age no exterior sobre a ciência, mas que efeitos de poder circulam entre os enunciados científicos; qual é seu regime interior 
de poder; como e por que em certos momentos ele se modifica de forma global. (FOUCAULT, 2012, p. 39).

Em uma aproximação com a área de Biblioteconomia e de Ciência da Informação, ao concebermos a verdade da informação como, por exemplo, uma classificação do conhecimento, as tabelas utilizadas para impor uma ordem de conhecimento exercem um tipo de congelamento proposital (e necessário) que é amparado por instituições e suas relações políticas, culturais, econômicas etc. Nesse sentido, um sistema de classificação levanta um ponto de vista, seja ele teórico e/ou prático, representando uma determinada porção de mundo em um dado momento. Como aborda Frohmann (2008, p. 26), “práticas documentárias institucionais lhe dão [ao documento/à documentação] peso, massa, inércia e estabilidade que materializa a informação de forma tal que ela possa configurar profundamente a vida social".

Isso significa que há, quando observamos objetos relativos à Biblioteconomia e à Ciência da Informação, o que González de Gómez (2007) chama de "intervenção seletiva das memórias sociais e formalizadas", uma vez que, necessariamente, existe uma formação impositiva de coleções documentais. Ou seja, a preservação do conhecimento passa por uma intencionalidade institucional, deveras disciplinar: “[...] outras inovações da escrita disciplinar se referem à correlação desses elementos, à acumulação dos documentos, sua seriação, à organização de campos comparativos que permitem classificar, formar categorias, estabelecer médias, fixar normas" (FOUCAULT, 1997, p. 182).

Isso é consonante ao que Buckland afirma no trabalho Information as thing, de 1991, ao concluir que informação-como-coisa é a única forma que a informação pode ser tratada pelos sistemas de informação; esse tipo de informação somente é gerada a partir de certa intencionalidade. A partir dessa ideia lidamos com a intencionalidade de uma autoridade enquanto autor, de uma autoridade enquanto indivíduo que lida com representação da informação e de uma autoridade institucional; autoridades conscientes e inconscientes.

Partindo da ideia de que há um deslocamento da análise da materialidade para além do material, compreendendo luta pela instauração de poder, a acepção proposta por Foucault (2003, p. 232) nos interessa: “[...] essas relações de poder utilizam métodos e técnicas muito, muito diferentes umas das outras, segundo as épocas e segundo os níveis". A era que vivemos é uma era de ciência, onde para que haja comunicação de pesquisas deve haver publicação, e a busca é por instituir verdades a partir de sistemas de legitimação de verdades: publicação e editoras. 


\section{Do documento como dispositivo da relação de poder}

Até o momento vimos o documento como um estabilizador da verdade. Se o documento é a perspectiva material da informação, esta, então, é a verdade enquanto discurso. É, podemos assumir, a verdade dada pela institucionalização de elementos autorizados e coercitivos postos em jogo e que obedecem determinadas regras. Não só obedecem, como também as instituem como perpetuação de um sistema. Pode ser considerado um dispositivo.

Embora, segundo Agamben (2009), Foucault não tenha desenvolvido a ideia de dispositivo, esta constitui noção primordial no trabalho do francês. Em um contexto histórico, Agamben analisa que Foucault retoma a ideia de positivé, precursora da noção de dispositivo, da diferenciação que Jean Hyppolite realiza, baseada em Hegel, entre religião natural e religião positiva. A primeira ligada à relação do homem com o divino; a segunda, também conhecida como histórica, está ligada ao "conjunto das crenças, das regras e dos ritos que numa determinada sociedade e num determinado momento histórico são impostos aos indivíduos pelo exterior" (AGAMBEN, 2009, p. 30-31).

Tomemos uma definição de dispositivo resumida por Foucault (2012, p. 367): "estratégias de relações de força sustentando tipos de saber e sendo sustentadas por eles". Assim, o autor pretende enxergar o dito e o não dito, aquilo que está além do discurso, a chamada épistémè ${ }^{5}$.

[...] em primeiro lugar, um conjunto decididamente heterogêneo que engloba discursos, instituições, organizações arquitetônicas, decisões regulamentares, leis, medidas administrativas, enunciados científicos, proposições filosóficas, morais, filantrópicas. Em suma, o dito e o não dito são elementos do dispositivo. O dispositivo é a rede que se pode estabelecer entre esses elementos. Em segundo lugar, gostaria de demarcar a natureza da relação que pode existir entre esses elementos heterogêneos. Sendo assim, tal discurso pode aparecer como programa de uma instituição, ou, ao contrário, como elementos que permite justificar e mascarar uma prática que permanece muda; pode ainda funcionar como reinterpretação dessa prática, dando-lhe acesso a um novo campo de racionalidade. Em suma, entre estes elementos, discursivos ou não, existe um tipo de jogo, ou seja, mudanças de posição, modificações de funções, que também podem ser muito diferentes. Em terceiro lugar, entendo dispositivo como um tipo de formação que, em um determinado momento histórico, teve como função principal responder a uma urgência. $\mathrm{O}$ dispositivo tem, portanto, uma função estratégica dominante. (FOUCAULT, 2012, p. 364-365).

Foucault vai adiante, ensinando que o dispositivo mantém, caracteristicamente, um objetivo estratégico, tomando para si o que pode ser entendido como uma "sobredeterminação

\footnotetext{
${ }^{5}$ A ideia de épistémè em Foucault está, grosso modo, ligada às relações estabelecidas em tipos de discursos em determinada época, sendo abandonada em favor da noção de dispositivo para compreender o dito e o não dito, podendo ser circunscrita como objeto arqueológico em Foucault.
} 
estratégica", ou seja, um processo de resposta a partir de um tipo de causa-efeito. Dessa maneira, constitui-se de uma constante rearticulação de um processo de atuar e de receber uma resposta. Processo que se coaduna em "preenchimentos estratégicos" com resultados não necessariamente esperados a partir de ações do dispositivo em questão.

O que temos, então, é o dispositivo como resposta a uma urgência, a uma indispensabilidade de pressupostos que, por necessidade daqueles que detêm o poder de instaurar o dispositivo, devem responder a uma contingência espaço-temporal de limitações, de coordenar barreiras e fronteiras onde o "agir-além" decreta a perda de sentido. Essa é a função estratégica, o estabelecimento de funções que sejam capazes de neutralizar um êmulo, constituindo-se em ações das relações de poder.

Ora, a própria resposta é um tipo de ação que acarreta em outra resposta, havendo uma troca constante entre agente e paciente através de uma interação que reengendra um processo sempre transitório e baseado em causas espaciais e temporais. Pensar nessas caraterísticas já é, por si só, buscar um encontro na interseção entre elementos que, inclusive em sua heterogeneidade, se coordenam e se desordenam, "o que supõe que se trata no caso de uma certa manipulação das relações de força" (FOUCAULT, 2012, p. 366-367), independentemente do tipo de ordem instaurada.

Outro elemento que Foucault nos apresenta é que o dispositivo "está sempre inscrito em um jogo de poder, estando sempre, no entanto, ligado a uma ou a configurações de saber que dele nascem mas que igualmente o condicionam" (FOUCAULT, 2012, p. 367). Aqui é importante lembrar que para Foucault os dispositivos têm gênese heterogênea, abarcando qualquer tipo de instituição, relação etc., podendo ser utilizados para se referir à dominação e certo tipo de subjetivação, possibilitando falar, por exemplo, em dispositivos de poder e dispositivos de sexualidade.

Ou seja, a inscrição de Foucault está na reapresentação de princípios de conduta, de comportamento do homem a partir de ligações que mantém com sociedade, sendo um tipo de vigilância que circunscreve o indivíduo em uma perspectiva de coerção. É esse sentido de imposição de vontades, de constrangimentos e de opressões que se situa a relação inicial percebida como dispositivo em Foucault, derivando, como dito, da "carga de regras, ritos e instituições impostas aos indivíduos por um poder externo, mas que se torna, por assim dizer, interiorizada nos sistemas das crenças e dos sentimentos" (AGAMBEN, 2009, p. 32). 
Agamben (2009, p. 32) apresenta, nesse sentido, uma síntese dos pontos elaborados por Michel Foucault em relação ao dispositivo, como forma de uma "relação entre os indivíduos como seres viventes e o elemento histórico, entendendo com este termo o conjunto das instituições, dos processos de subjetivação e das regras em que se concretizam as relações de poder":

a) É um conjunto heterogêneo, linguístico e não-linguístico, que inclui virtualmente qualquer coisa no mesmo título: discursos, instituições, edifícios, leis, medidas de polícia, proposições filosóficas etc. O dispositivo em si é a rede que se estabelece entre esses elementos.

b) O dispositivo tem sempre uma função estratégica concreta e se inscreve sempre numa relação de poder.

c) Como tal, resulta do cruzamento de relações de poder e de relações de saber.

Assim, embora Foucault não tenha trabalhado com "universais", dispositivos, na visão de Agamben, tomam o lugar desses: "não simplesmente esta ou aquela medida de segurança, esta ou aquela tecnologia do poder, e nem mesmo uma maioria obtida por abstração; antes, [...] 'a rede [...] que se estabelece entre estes elementos' (AGAMBEN, 2009, p. 34) [...] os dispositivos devem sempre implicar um processo de subjetivação, isto é, devem produzir o seu sujeito" (AGAMBEN, 2009, p. 38).

Agamben (2009, p. 40) propõe uma interpretação da ideia foucaultiana de dispositivo a partir de uma separação entre os seres vivos e os dispositivos de controle, sendo os primeiros "capturados" pelos segundos. Desse modo, um dispositivo pode ser compreendido como "qualquer coisa que tenha de algum modo a capacidade de capturar, orientar, determinar, interceptar, modelar, controlar e assegurar os gestos, as condutas, as opiniões e os discursos dos seres viventes".

A ideia de dispositivo vai além das instituições de controle, mas atua nas mais variadas esferas que criam uma subjetivação do ser. Qualquer que seja o dispositivo - uma lei, uma linguagem, as horas de trabalho, um discurso etc. - atua sobre o ser vivente de modo a lhe criar e transformar enquanto ser. $\mathrm{O}$ "sujeito [...] resulta da relação [...] entre os viventes e os dispositivos" (AGAMBEN, 2009, p. 41).

Isso pode ser ampliado se pensarmos que apesar dos fatores tecnológicos terem sido preponderantes para transformações sociais, facilitando a retroalimentação de uma evolução 
constante, há de se pensar que escondem as características mais abstratas (mas com implicações práticas) das inter-relações sociais existentes. Compreender que o documento se fixa como uma forma oriunda de situações sociais, culturais, políticas, econômicas de uma época, permite entender a reprodução de discursos que controlam e disseminam o poder (FREITAS, 2012), principalmente em época onde a tecnologia avança constantemente.

\section{Das percepções sobre o poder para um futuro escrutínio sobre ao acesso aberto}

O que levantamos até o momento, Foucault estabelece a partir de uma crítica contra a impossibilidade de agregação de saberes que não desfrutam de poder dentro da sociedade. $\mathrm{Ou}$ seja, se o poder que determina uma dinâmica na sociedade está ligado a um tipo de validação do conhecimento científico e seus produtores têm a possibilidade de chancelar ou não determinado conhecimento, é estabelecida a crença de que o que está fora desse "círculo virtuoso" está fora do saber válido.

Os documentos, enquanto produções acadêmicas, técnicas e científicas, apresentam caraterizações como as já atribuídas ao sentido de verdade por Foucault (2012), a saber: estão centradas na forma do discurso da ciência e das instituições produtoras; sofrem ações políticas e econômicas; são produto para difusão e produto para consumo; há sempre um poder regulador que age sobre; e são matéria de luta política e social.

O problema político essencial para o intelectual não é criticar os conteúdos ideológicos que estariam ligados à ciência ou fazer com que sua prática científica seja acompanhada por uma ideologia justa; mas saber se é possível constituir uma nova política de verdade. O problema não é mudar a 'consciência' das pessoas, ou o que elas têm na cabeça, mas o regime político, econômico, institucional da produção da verdade. (FOUCAULT, 2012, p. 54).

As coisas não são carregadas de elementos vazios ou produzidos por elas mesmas. Há uma complexidade histórica, política, econômica, cultural, social, entre outras, que as constrói e as carrega. Assim sendo, a própria estrutura da comunicação científica é como um santuário da exteriorização de ideias, sendo um processo fundamentador do fazer ciência.

Poderíamos colocar esse entendimento a partir da impossibilidade de ausência de poder mesmo na criação do documento e da seleção de fontes, estas já sendo as primeiras institucionalizações. Como aborda Murguia (2010, p. 137), 
[...] instituição não significa unicamente aquilo que é instituído pela lei ou pela tradição. A instituição também é o lugar onde a ordem ou a tradição se atualizam pelos seus agentes, com suas práticas e suas representações. Sempre em contínuas associações e montagens, dando lugar ao coletivo. (MURGUIA, 2010, p. 137).

Encararemos o documento como objeto de análise da Biblioteconomia e da Ciência da Informação - e aqui estamos nos detendo ao documento científico em geral na forma de artigo científico - e balizador de uma estrutura, obviamente científica, que produz conhecimento e é insumo para geração de novos conhecimentos. Só pode ser insumo, pelo aporte que vimos, através de uma regularização que o valide como informação para um campo e que permita-o fluir de forma sistemática, contínua, sem a existência de barreiras que impeçam sua disseminação.

A relação existente entre o documento e a institucionalização estruturante é uma relação dependente. A ciência tem como cerne a comunicação científica e a apropriação do direito de atuar como verdade parte de um princípio de validação, de creditação atribuída a avaliadores e posteriormente a avaliações e chancelas públicas de seus leitores, de sua comunidade científica.

Ora, a comunicação científica precisa estar amparada por um sistema que comporte seus processos avaliativos e de divulgação. Os grupos editorais que dominam a cena internacional mantêm um sistema que nasce com o sentido de fazer uma verificação metodológica e científica do trabalho conduzido, constituindo-se uma autoridade científica validatória.

Diferentemente da autoria como responsabilidade do conhecimento científico, a autoridade aqui está pautada em um tipo de tradição onde o editor científico detém o mercado e a tradição em seu favor. É uma tentativa constante de manter o poder que já o instituiu como grande divulgador do saber verdadeiro, como distribuidor do conhecimento científico que deve e que pode ser utilizado para outras pesquisas.

[...] a verdade não existe fora do poder ou sem poder [...]. A verdade é deste mundo; ela é produzida nele graças a múltiplas coerções e nele produz efeitos regulamentados pelo poder. Cada sociedade tem seu regime de verdade, sua "política geral" de verdade: isto é, os tipos de discurso que ela acolhe e faz funcionar como verdadeiros; os mecanismos e as instâncias que permitem distinguir os enunciados verdadeiros dos falsos, a maneira como se sanciona uns e outros; as técnicas e os procedimentos que são valorizados para obtenção da verdade; o estatuto daqueles que têm o encargo de dizer o que funciona como verdadeiro. (FOUCAULT, 2012, p. 51-52).

A existência de uma estrutura que domina o saber científico, aquele que é válido, consagra os conglomerados editoriais como centenárias fontes de publicação de conhecimentos. A ciência, como atividade que coordena os processos de conhecer no ocidente, está balizada, geralmente, em sistemas pagos, caríssimos, que são sustentados por governos e pesquisadores 
que investem grandes somas de capital para dispor de acesso à informação produzida e avaliada por outros pesquisadores.

Por exemplo: a CAPES (Coordenação de Aperfeiçoamento de Pessoal de Nível Superior) mantém o Portal de Periódicos cujo público-alvo gira em torno de 6 milhões de indivíduos, entre professores, pesquisadores, técnicos e alunos de graduação e pós-graduação. O custo do portal em 2013 foi de aproximadamente 94 milhões de dólares e em 2014 de cerca de $\mathrm{R} \$ 233$ milhões $^{6}$ com 285 mil acessos diários ao portal ${ }^{7}$. Dados de 2015 indicam que o custo para o país foi em torno de U\$0,27 por abstract (resumo) e U\$1,59 por download de artigo. Para 2016 o orçamento aprovado para o Portal foi de 334 milhões de reais ${ }^{8}$.

É possível notar o alto investimento empregado a cada ano para manutenção do Portal de Periódicos, fazendo com que o custo do conhecimento seja fator de alto impacto na política de pesquisa e educação brasileira, uma vez que seria impossível que diversos estudos fossem realizados sem que os interessados pudessem ter acesso ao que é publicado em outros países. Via inversa, para que se possa ter visibilidade do trabalho desenvolvido no Brasil, os pesquisadores também são compelidos à publicação nesses periódicos.

Adicionamos a isso que o acesso ao Portal se dá via acesso eletrônico a documentos digitais. Isso faz com que a materialização da informação, além dos meios institucionais, agregue o fator tecnológico, ou seja, documentos "que são produzidos por máquinas, alimentados em outras máquinas e que automaticamente produzem efeitos que configuram nossas vidas" (FROHMANN, 2008, p. 30).

Foi nas duas últimas décadas dos anos 1900 que o processo comercial do conhecimento tomou tamanho antes não experimentado devido ao crescente acúmulo de conhecimento científico e, por consequência, da literatura científica. Dada a demanda de publicação, as editoras científicas, a partir de uma relação mercadológica, viram a possibilidade de aumento no preço das revistas, limitando o acesso daqueles que não dispõem de verbas para compra de assinaturas. Esse processo pode acarretar "numa perda de eficiência do sistema de comunicação

\footnotetext{
${ }^{6}$ Dados obtidos em: http://pt.slideshare.net/sibi_ufrj/portal-de-peridicos-elenara-20140424

${ }^{7}$ Dados obtidos em: https://periodicos.capes.gov.br/images/documents/Apresenta\%C3\%A7\%C3\%A30\%20Portal\%20de\%20Peri\%C3 \%B3dicos_Elenara\%20Almeida.pdf

${ }^{8}$ Dados obtidos em: https://periodicos.capes.gov.br/?option=com_pnews\&component=Clipping\&view=pnewsclipping \&cid=557\&m $\underline{\mathrm{n}=0}$
}

InCID: R. Ci. Inf. e Doc., Ribeirão Preto, v. 8, n. 2, p. 25-41, set. 2017/fev. 2018. 
da ciência e em limitações ao impacto e reconhecimento dos resultados alcançados pelos investigadores e as instituições onde trabalham", aponta Rodrigues (2004, p. 27).

O que há em relação a isso, como alternativa postulada pelo acesso aberto, é uma resistência constante contra a hegemonia dos processos editoriais custosos. São alternativas buscadas como forma de disputa pelo que podemos chamar "socialização do saber". Estamos aqui numa disputa pela estrutura ética e política de uma forma de rompimento de uma relação que é custosa e materialmente discriminatória entre os que podem pagar pelo acesso e os que não têm essa condição, uma vez que quem está fora do círculo acadêmico, está excluído do acesso.

Como anota González de Gómez (2011) ao discutir a relação existente entre universidade e a sociedade da informação, para produzir conhecimento há necessidade de consulta à informação, ao conhecimento e/ou aos dados. São os próprios produtores que validam conhecimento científico, aferindo a verdade do saber proposto por outros pesquisadores. Publicar e avaliar são medições que a ciência impõe a seus membros.

Do mesmo modo que o discurso se caracteriza como uma prática que está vinculada à determinadas regras conexas à própria prática, a publicação em periódicos científicos advém da própria sistemática da comunicação científica. Assim, grandes editoras e periódicos que são outorgados como gatekeepers da difusão desse conhecimento se mantêm como tal, alicerçados em uma organização de publicação que está ligada a uma regulação de e no poder.

A implicação direta é a existência de uma

[...] dimensão mercantil que o conhecimento científico assume, tanto pelo capital simbólico que gera, ao ampliar prestígio e reconhecimento, quanto pela relação mercantil direta que pode assumir, por exemplo, ao restringir o acesso dos usuários dos resultados das pesquisas, impondo a cobrança de pagamento, o que caracteriza a produção científica como uma produção individual e apropriação como propriedade privada. (TREIN; RODRIGUES, 2011, p. 783).

Se há uma estrutura firmada como dominante, há possibilidade de forças se insurgirem contra ela. Se essa estrutura é um poder institucionalizado, há formas de atingi-la. Foucault (2003, p. 232) já alertava para a possibilidade de revolta contra o que é instituído e o cuidado que isso deve gerar: “[...] as relações de poder suscitam necessariamente, apelam a cada instante, abrem a possibilidade a uma resistência, e é porque há possibilidade de resistência e resistência real que o poder daquele que domina tenta se manter com tanto mais força, tanto mais astúcia quanto maior for a resistência" (FOUCAULT, 2003, p. 232). 
Então a verdade não é uma busca por uma coisa que permita compreender a essência do assunto de forma unívoca, sem erros e com indubitável confiança. A verdade existe dentro das

relações de poder. É, assim, um estatuto da verdade que age e reage a partir do poder que a instaura ou é demandado a partir dela. A criação do documento é a noção de produção de uma verdade (FOUCAULT, 2003). Essas produções de verdade são criadoras, propulsoras de novas produções de verdades, tecendo uma rede de efeitos de poder que as unem e que atuam sobre nós.

Seguindo essa linha, a forma como Foucault concebe o enunciado - aquilo que só pode ser dito por entidades que detêm posição para dizê-lo - é próxima a uma prática onde a publicação em periódicos já consagrados fomenta a possibilidade de ocupar uma posição, um lugar institucional. Ou seja, a utilização de dispositivos - neste caso, os periódicos científicos - extrapola o indivíduo, assumindo a possibilidade de enxergar o campo através de sua perspectiva institucionalizante e institucionalizada em que as ligações formam o coletivo.

\section{Considerações parciais, comentários finais e perspectivas futuras}

Nosso trabalho aqui é partir para uma investigação que não se encerra nela mesma, visando investigar as bases teóricas, conceituais e metodológicas que dizem respeito à crise na circulação do conhecimento. Entendemos que esse trabalho se inicia pela discussão do documento não enquanto um tipo de suporte de informação, mas como um dispositivo de ação, de perspectivas sociais que devem ser esquadrinhadas de forma sistemática.

A análise do documento - em especial o periódico científico - possibilita focalizar aspectos relacionais a ele e ao que assume como verdade, uma vez que atua institucionalmente. Permite observar que o documento, e a intenção de suas relações sociais, políticas, éticas, econômicas, culturais etc., está colocado para além da sua materialidade enquanto suporte, estabelecendo-o como construto social. Por exemplo: as ligações existentes entre o acesso aberto e o acesso pago estão colocadas para fora do alcance do documento per se, embora se materializem nele. As questões ideológicas, de ponto de vista, de uma cultura de disseminação ou de retenção de conhecimento, de luta de forças de instituições bilionárias que detêm amplo poder sobre o sistema de comunicação científica e a luta contra esse tipo de poder.

Se observarmos a ideia de que não há espaço sem poder, isto é, as sociedades são constituídas com poder, entre dominantes e dominados, a própria constituição do campo social 
possibilita ver um espaço de lutas. E só pode haver luta se há poder. Só podemos pensar em crise, em ruptura, se avistarmos a chance de "pensar contra o sistema", de uma insurgência contra a reprodução da ordem social estabelecida.

A questão do documento científico como instaurador de uma crise na comunicação científica vai muito além de uma questão teórica. É um quesito que age na experiência do sujeito, na sua constituição enquanto ser social, e não necessariamente com a culposidade ou com a inocência de agentes a partir de determinada perspectiva. É premissa a investigação sobre como se constituem campos, agentes, ações etc. Entendemos que iniciar a investigação pelas potencialidades do documento é sistematizar um dispositivo controlado e controlador, produto e produtor, instaurado e instaurador, ordenado e ordenador, causa e efeito.

É importante relatar que, a partir do que buscamos esclarecer, não agimos com um senso de que o homem solitário é feitor de suas atitudes sem que o mundo que o cerca interfira nele e ele interfira no mundo. Pelo contrário, argumentamos que ser artífice de si mesmo não significa uma separação da sociedade, uma negação, mas, sim, reconhecer na sociedade e na existência de outros seres a capacidade de se conhecer e construir novos modos de viver melhor.

O documento se coloca como um dispositivo do regime de verdade, ou seja, faz parte de um "conjunto de procedimentos regulados para a produção, a lei, a repartição, a circulação e o funcionamento dos enunciados" (FOUCAULT, 2012, p. 54). Nesse sentido o documento, para se apresentar como um conjunto de verdades, é sempre um conjunto de forças arregimentadas para se enquadrar em determinadas situações de poder, de acordo com a verdade da sociedade que ele faz ou quer fazer parte, construindo um regime em vigor.

Sendo o documento a materialização das relações que se estabelecem para uma verdade, conhecer os procedimentos que o constroem para além da sua materialidade é - assim consideramos - passo inicial basilar na constituição de nossa pesquisa. A compreensão do objeto e, principalmente, de sua construção permite que sejam vislumbradas maneiras de olhar a instauração a partir da palavra, do documento, da informação, da consciência e da inconsciência. A verdade instituída passa a ser enxergada a partir de uma relação de forças que estão presentes historicamente no mundo. Essas forças também que ganham sua representação no documento. 


\section{Referências}

AGAMBEN, G. O que é um dispositivo? In: O que é o contemporâneo? e outros ensaios. Chapecó: Argos, 2009.

ARAÚJO, I. L. Do signo ao discurso: introdução à filosofia da linguagem. São Paulo: Parábola, 2011.

BUCKLAND, M. Information as thing. Journal of the American Society for Information Science, v. 42, n. 5, p. 351-360, 1991.

GONZÁLEZ DE GÓMEZ, M. N. A universidade e a "sociedade da informação". Revista Digital de Biblioteconomia e Ciência da Informação, v. 9, n. 1, p. 225-242, jul./dez. 2011.

GONZÁLEZ DE GÓMEZ, M. L. Novas configurações do conhecimento e validade da informação. In: ENCONTRO NACIONAL DE PESQUISA EM CIÊNCIA DA INFORMAÇÃO, 8., 2007, Salvador. Anais... Salvador: ENANCIB, 2007.

FOUCAULT, M. A ordem do discurso. 24. ed. São Paulo: Loyola, 2014. Microfísica do poder. 25. ed. São Paulo: Graal, 2012.

Poder e saber. In: Ditos \& escritos IV: estratégia, poder-saber. 2. ed. São Paulo: Forense Universitária, 2003.

Vigiar e punir: nascimento da prisão. 41. ed. Petrópolis: Vozes, 1997.

FREITAS, L. S. Documento e poder: uma arqueologia da escrita. Morpheus - Revista Eletrônica em Ciências Humanas, ano 9, n. 14, p. 58-73, 2012.

FROHMANN, B. O caráter social, material e público da informação. In: FUJITA, M. S. L.; MARTELETO, R. M.; LARA, M. L. G. A dimensão epistemológica da Ciência da Informação e suas interfaces técnicas, políticas e institucionais nos processos de produção, acesso e disseminação da informação. São Paulo: Cultura Acadêmica, 2008.

LE GOFF, J. Documento/monumento. In: História e memória. Campinas: Unicamp, 1996.

MURGUIA, E. I. Documento e diversidade: produção, diversidade e verdade. In: FREITAS, L. S.; MARCONDES, C. H.; RODRIGUES, A. C. (Org.). Documento: gênese e contextos de uso. Niterói: EDUFF, 2010. (Estudos da Informação; 1).

RODRIGUES, E. Acesso livre ao conhecimento: a mudança do sistema de comunicação da ciência e os profissionais de informação. Cadernos BAD, v. 1, 2004.

TREIN, E.; RODRIGUES, J. O mal-estar na Academia: produtivismo científico, o fetichismo do conhecimento-mercadoria. Revista Brasileira de Educação, v. 16, n. 48, p. 769-819, set./dez. 2011. 